\title{
Sistema radicular de aceroleiras propagadas por sementes e por estacas
}

\section{Root system of West Indian cherry plants propagated by seeds and cuttings}

\author{
Carmen Silvia Vieira Janeiro Neves ${ }^{1 *}$; Neusa Maria Colauto Stenzel' \\ Cristiane de Conti Medina ${ }^{1}$; Ives Massanori Murata ${ }^{3}$; Andrey Vetorelli Borges ${ }^{4}$
}

\section{Resumo}

O trabalho teve o objetivo de avaliar e comparar a quantidade e a distribuição das raízes de plantas de aceroleira (Malpighia emarginata) com 4,5 anos de idade, em Latossolo Vermelho distroférrico, propagadas por: a) semeadura, e posterior enxertia; b) estaquia. Para a avaliação das raízes utilizou-se o método da trincheira, aberta em duas direções: na linha e na entrelinha, até metade do espaçamento entre plantas. Nas trincheiras foram tomadas imagens de $25 \times 25 \mathrm{~cm}$ e avaliadas com o programa SIARCS. Foi avaliada a densidade de raízes finas ( $<0,5 \mathrm{~cm}$ de diâmetro) e de raízes grossas ( $>0,5 \mathrm{~cm}$ de diâmetro) por área de trincheira. Não houve diferença entre os dois sistemas de propagação, na linha de plantio, para a densidade de raízes finas. Na entrelinha, as plantas propagadas por estaca apresentaram maior densidade de raízes finas na profundidade $0-0,25 \mathrm{~m}$, enquanto que nas propagadas por semente apresentaram mais raízes finas nas profundidades $0,25-0,50 \mathrm{e} 0,50-0,75 \mathrm{~m}$. Para as raízes grossas, as plantas propagadas por semente apresentaram maior densidade que o tratamento estaca na linha de plantio para as profundidades 0,00-0,25 e 0,25-0,50 m e na média geral da densidade de raízes (linha + entrelinha).

Palavras-chave: Malpighia emarginata, propagação, raízes, trincheira

\begin{abstract}
This research work had as objective to evaluate and to compare the amount and the distribution of the roots of 4.5 years old West Indian Cherry plants, in a clayey Typic Hapludox, propagated by: a) seeds (and subsequent grafting); b) cuttings. It was used the trench profile method, in the planting rows and in the inter-rows, covering half spacing. Images of $25 \times 25 \mathrm{~cm}$ were taken in the trenches and evaluated with the SIARCS program. The density of fine $(<0.5 \mathrm{~cm}$ of diameter) and thick roots $(>0.5 \mathrm{~cm}$ of diameter $)$ were assessed. There was no difference between the two propagation systems for the density of fine roots in the planting row. The plants propagated by cuttings presented larger density of fine roots in the depth $0-0.25 \mathrm{~m}$; and plants propagated by seeds showed more roots in the depths $0.25-0.50$ and $0.50-0.75$ $\mathrm{m}$ in the inter-row. The plants propagated by seeds presented larger density of thick roots than plants propagated by cuttings in the layers $0-0.25$ and $0.25-0.50 \mathrm{~m}$ in the row and in the general density of roots (row + inter-row).
\end{abstract}

Key words: Malpighia emarginata, propagation, roots, trench profile wall

\footnotetext{
1 Eng ${ }^{\mathrm{a}}$. Agra ., Dr., Professora do Dep. de Agronomia, Universidade Estadual de Londrina, C.P. 6001, CEP 86.051-990, Londrina, PR. Fone/Fax: (43) 3371-4697; Bolsista CNPq; e-mail: csvjneve@uel.br

2 Enga . Agra., MSc., Doutoranda em Agronomia, Instituto Agronômico do Paraná - IAPAR - Londrina, PR.

3 Mestrando em Agronomia, UEL, Bolsista CAPES

4 Acadêmico de Agronomia, UEL, Bolsista CNPq/PIBIC

* Autor para correspondência.
} 
A aceroleira (Malpighia emarginata D.C.) é um arbusto originário da América Tropical, cujos frutos possuem alto teor de acido ascórbico, o que impulsionou seu cultivo no Brasil (Araujo \& Minami, 1994). Na região Sul, o Paraná é o principal produtor de acerola (Stenzel \& Motter, 1995).

A aceroleira pode ser propagada por sementes, estaquia ou enxertia. De acordo com Gonzaga Neto \& Soares (1994), a estaquia assegura precocidade de produção e transmissão das características da planta matriz, enquanto que a enxertia possibilita, além dessas vantagens, a formação de um sistema radicular vigoroso, que explora maior volume de solo e que, por apresentar raiz pivotante, dá maior firmeza à planta em locais sujeitos a ventos fortes.

Kolesnikov (1971) classificou as raízes das plantas frutíferas, quanto ao diâmetro, em raízes fibrosas (curtas e finas, com até alguns centímetros de comprimento e diâmetro de até alguns milímetros) e raízes estruturais (longas e mais grossas, com comprimento de até alguns metros e diâmetro de até vários centímetros). Estas classes correspondem, respectivamente, aos crescimentos primário e secundário das raízes (Esau, 1976). As raízes mais finas tem como função principal a absorção de água e nutrientes.

O presente trabalho teve como objetivo avaliar e comparar a quantidade e a distribuição das raízes fibrosas e estruturais de plantas de aceroleira, propagadas por semeadura, e posterior enxertia, ou por estaquia, nas condições do Norte do Paraná.

O trabalho foi realizado em Londrina, PR (coordenadas $23^{\circ} 23^{\prime} \mathrm{S}$ e $51^{\circ} 11^{\prime} \mathrm{W}$ ). O clima da região, segundo a classificação de Köppen, é do tipo Cfa, subtropical úmido, com chuvas em todas as estações, podendo ocorrer seca no período de inverno. As plantas avaliadas estavam localizadas em pomares formados por coleções de aceroleiras na Estação Experimental do Instituto Agronômico do Paraná e na Fazenda Escola da Universidade Estadual de Londrina. O solo foi classificado como Latossolo Vermelho distroférrico. As plantas do pomar do IAPAR foram propagadas por semeadura e posteriormente enxertia de garfagem de fenda cheia. As sementes foram obtidas em pomares comerciais (também propagados por sementes), de plantas produtivas e em boas condições fitossanitárias. As plantas da UEL foram propagadas por estaquia. As copas das plantas do IAPAR eram dos genótipos Camb-6, Cia-2 e Cia-3, e as plantas da UEL eram dos genótipos Dominga, Ligia e Natália. Todas as plantas por ocasião da avaliação das raízes estavam com 4,5 anos de idade. O espaçamento utilizado foi de 4 x 2 m para o pomar da UEL e de 4 x 4 m no pomar do IAPAR.

Para a avaliação das raízes utilizou-se a método da trincheira ou perfil (Böhm, 1979), com nove repetições (trincheiras) inteiramente ao acaso por tratamento (tipo de propagação). As trincheiras foram abertas em duas direções: a) perpendiculares à linha de plantio (entrelinha), com comprimento de metade do espaçamento entre as linhas; b) paralelas à linha de plantio (linha) com comprimento de metade do espaçamento entre as plantas. As trincheiras foram abertas a $10 \mathrm{~cm}$ do tronco das plantas, com profundidade de 1,0 m. As raízes foram expostas com escarificador em forma de rolo, com pregos sem cabeça e coloridas com tinta látex branca, para se obter maior contraste entre o solo e as raízes. Foi afixada ao perfil uma moldura de madeira dividida por fios de nylon em quadrículas de 25 por $25 \mathrm{~cm}$ (Cintra \& Neves, 1996). De cada quadrícula foi obtida uma imagem com câmera fotográfica digital. As imagens foram analisadas para a determinação do comprimento das raízes finas (menores que 0,5 cm de diâmetro) com o programa SIARCS (Crestana et al., 1994) e do número de raízes grossas (maiores que $0,5 \mathrm{~cm}$ de diâmetro) em cada quadrícula, por profundidade $(0,00-0,25 ; 0,25-0,50 ; 0,50-0,75 ; 0,75-$ $1,00 \mathrm{~m}$ ) e por trincheira, na linha e na entrelinha. Os valores obtidos de comprimento e de número de raízes foram transformados em densidade de raízes por $\mathrm{m}^{2}$ de superfície do perfil, conforme proposto por Zanette \& Dron (1989). O delineamento experimental utilizado foi o inteiramente casualizado, sendo as médias comparadas pelo teste $t$. 
Observa-se que as raízes mais finas $(<0,5 \mathrm{~cm}$ de diâmetro) tiveram densidade estatisticamente equivalente para os dois sistemas de propagação na linha de plantio (Tabela 1). Entretanto, na entrelinha da cultura, observa-se que o sistema de propagação por estaca foi significativamente superior na profundidade $0-0,25 \mathrm{~m}$, enquanto que a propagação por semente foi significativamente superior nas profundidades $0,25-0,50$ e 0,50-0,75 m. Estes resultados estão de acordo com Kolesnikov (1971), que observou que o sistema radicular de plantas propagadas por sementes tem maior capacidade de atingir camadas mais profundas do solo do que de plantas propagadas vegetativamente. Entretanto, para Eucalyptus, Mello et al. (1998) encontraram que o desempenho das plantas quanto à quantidade de raízes foi mais influenciado pelo potencial genético dos clones avaliados do que pelo sistema de propagação.
Para as raízes estruturais ( $>0,5 \mathrm{~cm}$ de diâmetro), o tratamento semente foi significativamente superior ao tratamento estaca na linha de plantio para as profundidades 0,00-0,25 e 0,25-0,50 m (Tabela 2), o que se refletiu na densidade média geral, que foi maior nas plantas propagadas por sementes.

Conclui-se que a densidade de raízes mais finas $(<0,5 \mathrm{~cm})$ é equivalente para as dois sistemas de propagação na linha de plantio. Na entrelinha, as plantas propagadas por estaca apresentam maior densidade de raízes finas na profundidade $0-0,25 \mathrm{~m}$, enquanto que nas propagadas por semente possuem mais raízes nas profundidades $0,25-0,50$ e $0,50-0,75 \mathrm{~m}$. Para as raízes mais grossas $(>0,5 \mathrm{~cm})$, o tratamento semente apresenta maior densidade que o tratamento estaca na linha de plantio para as profundidades 0,00 0,25 e 0,25-0,50 m e na média geral da densidade de raízes, considerando linha + entrelinha.

Tabela 1 - Densidade de raízes $(<0,5 \mathrm{~cm}$ de diâmetro) de aceroleiras propagadas por semente ou estaquia, nas diferentes profundidades, na linha, na entrelinha e no total da trincheira. Londrina - PR, 2000.

\begin{tabular}{|c|c|c|}
\hline & \multicolumn{2}{|c|}{ Tratamentos } \\
\hline & Semente & Estaca \\
\hline & \multicolumn{2}{|c|}{ Densidade de Raízes $<0,5 \mathrm{~cm}\left(\mathrm{~cm} \mathrm{~m}^{-2}\right)$} \\
\hline \multicolumn{3}{|l|}{ Linha (L) } \\
\hline Profundidade $0-0,25 \mathrm{~m}$ & $1.592,38 \mathrm{a}^{*}$ & $2.129,90 \mathrm{a}$ \\
\hline Profundidade $0,25-0,50 \mathrm{~m}$ & $631,83 \mathrm{a}$ & $698,50 a$ \\
\hline Profundidade $0,50-0,75 \mathrm{~m}$ & $444,07 \mathrm{a}$ & $382,99 a$ \\
\hline Profundidade $0,75-1,00 \mathrm{~m}$ & $345,80 \mathrm{a}$ & $348,45 \mathrm{a}$ \\
\hline Média Linha & $753,50 \mathrm{a}$ & $889,96 \mathrm{a}$ \\
\hline \multicolumn{3}{|l|}{ Entrelinha (EL) } \\
\hline Profundidade $0-0,25 \mathrm{~m}$ & $1.415,97 \mathrm{~b}$ & $1.869,93 \mathrm{a}$ \\
\hline Profundidade $0,25-0,50 \mathrm{~m}$ & $887,95 \mathrm{a}$ & $541,01 \mathrm{~b}$ \\
\hline Profundidade $0,50-0,75 \mathrm{~m}$ & $559,86 \mathrm{a}$ & $393,12 \mathrm{~b}$ \\
\hline Profundidade $0,75-1,00 \mathrm{~m}$ & $353,96, \mathrm{a}$ & $318,18 \mathrm{a}$ \\
\hline Média Entrelinha & $804,44 \mathrm{a}$ & $780,56 \mathrm{a}$ \\
\hline Média Geral (L + EL) & $778,97 \mathrm{a}$ & $835,26 a$ \\
\hline
\end{tabular}

*Médias seguidas da mesma letra, na linha, não diferem entre si pelo teste t a 10\% de significância. 
Tabela 2 - Densidade de raízes ( $>0,5 \mathrm{~cm}$ de diâmetro) de aceroleiras propagadas por semente ou estaquia, nas diferentes profundidades, na linha, na entrelinha e no total da trincheira. Londrina - PR, 2000.

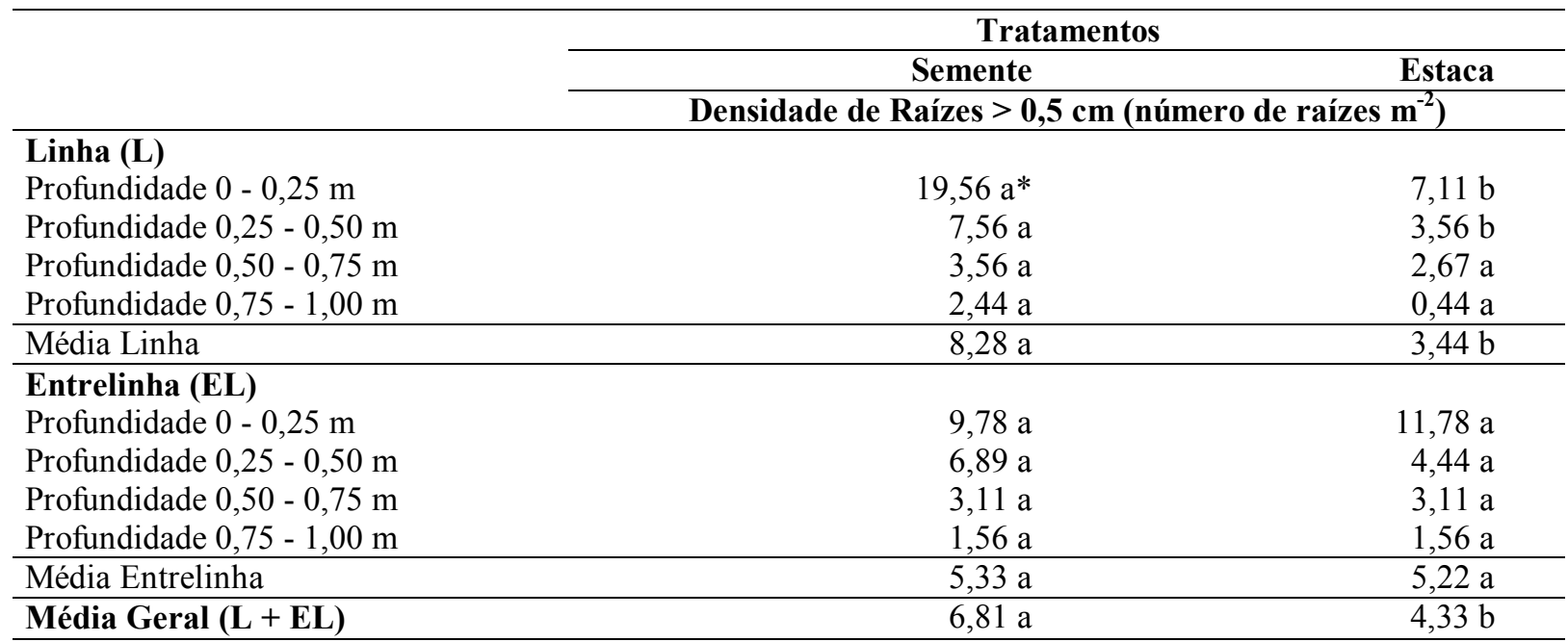

\section{Referências Bibliográficas}

ARAÚJO, P.S.R.; MINAMI, K. Acerola. Campinas: Fundação Cargill, 1994. 81p.

BÖHM, W. Methods of studying root systems. Berlin: Springer-Verlag, $1979.188 \mathrm{p}$.

CINTRA, F.L.D.; NEVES, C.S.V.J. Aspectos metodológicos do estudo do sistema radicular de plantas perenes através de imagens. Boletim Informativo da Sociedade Brasileira de Ciência do Solo, Campinas, v.21, n. 3, p. 91-94, 1996.

CRESTANA, S.; GUIMARÃES, M. F.. JORGE, L.A.C.; RALISCH, R.: TOZZI, C.L: TORRE, A.; VAZ, C.M.P. Avaliação da distribuição de raízes no solo auxiliada por processamento de imagens digitais. Revista Brasileira de Ciência do Solo, Campinas, v. 18, p. 365-371, 1994.

ESAU, K. Anatomia das plantas com sementes. São Paulo: Edgard Blucher, 1976. 293 p.

GONZAGA NETO, L.; SOARES, J.M. Acerola para exportação; aspectos técnicos da produção. Brasilia: EMBRAPA- SPI, 1994. 43 p. (Série Publicações Técnicas FRUPEX; 10).
KOLESNIKOV, V.A. The root system of fruit plants. Moscow: MIR, 1971.269p.

MELLO, S.L.M.; GONÇALVES, J.L. de M.; OLIVEIRA, L.E.G. de. Características do sistema radicular em povoamentos de eucaliptos propagados por sementes e por estacas. Scientia Forestalis, Piracicaba, n., 54, p.1728, 1998.

STENZEL, N.M.C.; MOTTER, A.A. Cultura de acerola no estado do Paraná; pesquisa e extensão. In: SÃO JOSÉ, A.R.: ALVES, R.E. Acerola no Brasil; produção e mercado. Vitória da Conquista: UESB. 1995. p. 130-132.

ZANETTE, F.; DRON, C. Método descritivo da distribuição espacial do sistema radicial da macieira (Malus domestica B., cv. Golden Delicious/ MM-106). In: CONGRESSO BRASILEIRO DE FRUTICULTURA, 10., Fortaleza, 1989. Anais... Fortaleza, Sociedade Brasileira de Fruticultura, 1989, p. 248-253. 